\title{
ANÁLISE DA RELAÇÃO DROGAS E ADOLESCENTES COMO EXPRESSÃO DA QUESTÃO SOCIAL NA SAÚDE PÚBLICA
}

\author{
${ }^{\star}$ Eliseane Cardoso Moura ${ }^{1}$
}

\begin{abstract}
RESUMO
O objetivo deste estudo foi analisar sobre a relação das drogas e adolescentes como expressão da questão social na saúde pública brasileira. O estudo apresentou uma breve contextualização sobre drogas no Brasil, sendo estas psicoativas e viciantes como contribuem de maneira destrutiva na vida dos adolescentes no âmbito familiar e social e da diversidade nos impactos sociais que influenciam na Saúde Pública brasileira identificados nos atendimentos realizados pelas redes de atenção de saúde pública e das internações realizadas pelo SUS para o público adolescente. Assim, pergunta-se quais os tipos de substâncias psicoativas e drogas comuns mais utilizadas pelos adolescentes e os impactos sociais que agravam a Saúde Pública no que é inerente ao uso de substâncias psicoativas entre adolescentes e jovens? Desta forma, o estudo utilizou-se de metodologia pura, com uma abordagem bibliográfica e exploratória, qualitativa, descritiva, considerando as contribuições de autores que abordam o tema, por meio de dados obtido através de artigos, periódicos e livros, como procurando demonstrar as causas e efeitos que as drogas psicoativas e maléficas inferem na vida dos adolescentes transformando seus comportamentos, atitudes e ações na sociedade associadas a contextos de violência extremas, brigas entre familiares e suicídios a essa população, e criam outras mazelas que compõem a vida social, educacional e pessoal de adolescentes e jovens. Sendo assim, a importância deste estudo visa contribuir para um amplo conhecimento da comunidade acadêmica, profissionais e estudiosos no assunto, sobre causas e efeitos das drogas na vida familiar e social dos adolescentes em vários contextos e assim mensurar os resultados propostos nesse estudo.
\end{abstract}

Palavras-chave: Adolescentes. Consequências. Drogas.

\section{1 - INTRODUÇÃO}

O estudo foi desenvolvido a partir do tema na proposição de analisar sobre a relação das drogas e dos adolescentes como expressão da questão social na saúde pública brasileira que inferem ao organismo físico e nas atitudes comportamentais dos adolescentes, tornando-se um problema de questão social na Saúde Pública brasileira e que abrange contextos de violências extremas na sociedade e mortes por suicídios de adolescentes.

Tem como objetivo principal apresentar os efeitos que permeiam a relação das drogas entre adolescentes e jovens. A motivação da escolha dessa temática foi pelos altos índices de envolvimento entre adolescentes e jovens com homicídios, violência extrema e suicídio.

\footnotetext{
${ }^{1}$ Assistente Social pelo Centro Universitário Estácio da Amazônia (2018); Pós-Graduanda em Saúde Pública pelo Instituto Prominas (2019); email: eliseane_@hotmail.com.
} 
Em face dessa realidade no país onde os números são alarmantes de mortes de adolescentes e jovens por arma branca, de fogo e por rivalidade de grupos que usam extrema violência evidenciadas por meio de veículos da imprensa como jornais e redes sociais. Neste sentido, foram construídas as questões que norteiam este trabalho, quais os tipos de substâncias psicoativas mais utilizadas pelos adolescentes e os impactos sociais que agravam a Saúde Pública no que é inerente ao uso de substâncias psicoativas entre adolescentes e jovens?

O texto está organizado com o objetivo de identificar os principais motivos e substâncias psicoativas mais utilizadas pelos adolescentes e jovens durante essas fases no Brasil, bem como da relação de efeito e causa pela utilização em ambientes como a casa, escola e espaços públicos.

Para alcançar os objetivos propostos, utilizou-se como recurso metodológico, a pesquisa bibliográfica, realizada a partir da análise de materiais já publicados na literatura e artigos científicos divulgados no meio eletrônico.

Para tanto, utilizou-se da pesquisa bibliográfica, exploratória e qualitativa, isso irá permitir o levantamento das informações e estudos para melhor compreensão do tema. Durante a pesquisa qualitativa, que visa não somente a qualidade e compreensão do assunto abordado para obter os resultados.

No conjunto das informações, a pesquisa bibliográfica como procedimento metodológico irá permitir o pesquisador a explorar outros autores e assim, contribuir na elucidação do tema.

\section{2 - A FASE DA ADOLESCÊNCIA E JUVENTUDE}

\section{Drogas no Brasil}

No Brasil, o uso de substâncias psicoativas entre adolescentes não é um tema novo a ser tratado, a diferença se faz pelos índices constantes que se agravam envolvendo internações e mortes de adolescentes em número cada vez maior e de faixa etária inferior a 15 anos.

Os acessos aos diversos tipos de drogas pelos adolescentes estão relacionados ao consumo da maconha, cocaína, tabaco, álcool, estimulantes, inalantes, ansiolíticos, alucinógenos, tranquilizantes, solventes e anfetamínicos 
que por diversas razões conseguem adentrar no ciclo das drogas para uso ou comercialização, sendo esta a opção de muitos adolescentes permanecerem no contexto das drogas.

Nesse sentido, vários autores abordam este assunto em contextos diferenciados sem dissociar a relação familiar ao primeiro uso com drogas (fatores genéticos), a ausência familiar que infere na insistência de seus usos (falta de relação afetiva com pais ou familiares próximos) e dentre outras razões a prática do uso coletivo por questões de identificação a determinados grupos sociais.

Ressalta-se que está associada a permanência da utilização ou comercialização de drogas em ambientes mais vulneráveis de desigualdades sociais atreladas ao efeito da dependência financeira aos que possuem poder de manter famílias inteiras em permanência do tráfico, envolvendo crianças e adolescentes nesse ciclo, pois a não permanência ou respostas ao tráfico levam famílias inteiras à morte por dever dinheiro ao tráfico seja pela comercialização ou consumo próprio e ainda, a cometerem o suicídio quando ameaçados. Conforme Santos \& Pratta, indicam:

\footnotetext{
De acordo com a Organização Mundial da Saúde - OMS (1965), a adolescência é definida como um período biopsicossocial que compreende a segunda década da vida (10 aos 20 anos). Esse também é o critério adotado pelo Ministério da Saúde (Brasil, 2007a) e pelo Instituto Brasileiro de Geografia e Estatística - IBGE (Brasil, 2007b). Já do ponto de vista do Estatuto da Criança e do Adolescente - ECA (Brasil, 2007c), o adolescer se estende dos 12 aos 18 anos (SANTOS \& PRATTA, 2012, p.168).
}

Neste contexto, observa-se que os parâmetros de faixas de idade divergem no que se refere quando se trata de adolescente, como base para este estudo, o Estatuto da Criança e do Adolescente irá prevalecer norteando os indicativos sobre o uso de drogas psicoativas entre adolescentes.

\section{3 - O UNIVERSO DAS DROGAS}

\section{Utilização de drogas por adolescentes e jovens}

O uso das drogas psicoativas entre crianças e adolescentes tem sido um tema tratado nas esferas governamentais e da sociedade como o todo, e tem se tornado um problema de ordem pública e social, quando suas interferências 
atingem os diversos contextos sociais dos sujeitos envolvidos quando se reconhece como uma epidemia nacional.

As informações prévias sobre o que venha a ser uma epidemia, trata-se tecnicamente, do aumento do número de casos de doenças ou fenômenos dos quais se tem conhecimento em determinadas localidades. E em sentido amplo, a epidemiologia é a ciência que estuda a frequência e fatores de determinados fenômenos associados à saúde da população. Nesse contexto, as drogas e o uso por adolescentes. Nesse sentido, o Estatuto da Criança e do Adolescente no Art. 3ำ, dispõe:

$\{\ldots\}$ a criança e o adolescente gozam de todos os direitos fundamentais inerentes à pessoa humana, sem prejuízo da proteção integral de que trata esta Lei, assegurando-se-lhes, por lei ou por outros meios, todas as oportunidades e facilidades, a fim de lhes facultar 0 desenvolvimento físico, mental, moral, espiritual e social, em condições de liberdade e de dignidade (BRASIL, Art.3ํ, 2018, s/p).

Partindo de uma breve análise do ECA no artigo $3^{\circ}$ em específico, é possível encontrar algumas situações de desigualdades sociais e falta de oportunidades igualitária em níveis regionais no contexto nacional brasileiro, é perceptível questões culturais, cor, etnias completarem essas diferenças na sociedade brasileira no contexto dos adolescentes, pois nem todos tem acesso à educação de qualidade, saúde e liberdade e porque não dizer de dignidade. Conforme Frasson,

\begin{abstract}
Nesse norte [...] as suas condições, pois atuam como líderes da comunidade, chefes do poder paralelo [...]. Com o passar do tempo, as comunidades e periferias se tornaram verdadeiras propriedades privadas de traficantes. E como a ação do Poder Público não chega nesses bairros, serviços como energia elétrica, água, esgoto e distribuição de remédios, são fornecidos e controlados pelos comandantes do tráfico (FRASSON, 2015, s/p).
\end{abstract}

Esta é uma realidade em várias regiões do Brasil, o aumento significativo da utilização do poder do tráfico em comunidades com vulnerabilidades sociais, mas que ocorre também, na atualidade nas classes sociais de grande poder aquisitivo. Nesse contexto, Alba Zaluar, afirma: 
Um dos principais problemas mundiais de hoje é a incapacidade de controlar o uso de drogas ilegais, [...] logística que impressiona pela sua eficácia. Diz-se que o mercado ilegal de drogas é hoje um dos maiores setores econômicos do mundo. Todavia, é apenas uma parte do sistema de funcionamento do crime-negócio, mais ou menos organizado, que funciona em diversos setores, utilizando redes e mecanismos similares para parecer operações limpas e legais (ZALUAR, 2007, p.32).

O envolvimento com o mundo das drogas tem chamado a atenção no sentido de que cada vez mais, crianças e adolescentes serem envolvidas com o intuito do crescimento do comércio do tráfico de drogas no país, pelo acesso ao dinheiro fácil e rápido. Nesse sentido, Veloso \& Abreu, afirmam:

[...] adotar uma perspectiva que vá além da compreensão desses sujeitos apenas como vítimas de uma sociedade cruel. Essas pessoas são portadoras de histórias de vida que lhes são únicas, são protagonistas do contexto em que vivem, mesmo que seja um contexto onde as relações sócio estruturais influenciem de forma bastante negativa. Sem essa compreensão torna-se tarefa difícil acreditar em qualquer mudança de vida por parte desses sujeitos (VELOSO \& ABREU, 2005, p.13).

Nessa perspectiva, a percepção que se tem subjetiva de cada situação do envolvimento de adolescentes com o mundo das drogas torna-se uma história de vida complexa e que tem início, meio e fim, que muitas vezes não possuem os melhores finais nessa triste realidade brasileira. Sendo assim, afirmam Santos \& Pratta:

\begin{abstract}
A drogadição, tomada como um sintoma psíquico, coloca o indivíduo frente à necessidade de compreender que significados essa formação sintomática embute, ou seja, o que ele busca revelar por meio do sintoma. Nessa linha de pensamento, considerando que os estudos epidemiológicos apontam que a maioria dos indivíduos começa a fazer uso de substâncias psicoativas na adolescência e que esse uso entre adolescentes tem sido cada vez mais intenso e precoce, é importante identificar os significados do sintoma, principalmente nessa fase do ciclo vital (SANTOS \& PRATTA, 2012, p.174).
\end{abstract}

Revela-se os sintomas da utilização das drogas, primeiramente, nos aspectos familiares, educacionais e comportamentais dos adolescentes, fazendo-os agir com violência extrema e mortes por suicídios e ainda, de fatores que condicionam nos aspectos educacionais como evasão escolar e violência física dentro das escolas contra professores, gestores e colegas. Segundo Marques \& Cruz, 
Todas as substâncias psicoativas usadas de forma abusiva produzem aumento do risco de acidentes e da violência, por tornar mais frágeis os cuidados de autopreservação, já enfraquecidos entre adolescentes. Esses riscos ocorrem especialmente com o uso do álcool, a droga mais utilizada nessa faixa etária. O álcool pode causar intoxicações graves, além de hepatite e crises convulsivas (MARQUES \& CRUZ, 2000, p.33).

Desse modo, percebe-se que a utilização contínua das drogas líquidas, injetáveis, e as que se são inaladas pelos adolescentes, aumenta gradativamente os riscos iminentes físicos a si e a outrem, e a dependência das drogas será mais suscetível a desenvolver outros tipos de doenças ocasionadas pelo uso frequente das drogas, como intoxicações que os levará a internações em instituições de saúde. Conforme Marques e Cruz,

A cocaína e as anfetaminas estimulam as ações dopaminérgica e
noradrenérgica, podendo produzir, durante a intoxicação, crises
convulsivas, isquemia cardíaca e cerebral, além de quadros
maniformes e paranóides. O uso crônico induz a síndromes
psiquiátricas semelhantes a depressão, ansiedade, pânico [...]
problemas pulmonares, como tosse, expectoração, pneumonia,
hemoptise, bronquioespasmo e edema pulmonar (MARQUES \&
CRUZ, 2000, p.33).

Diante de todos esses efeitos, causas e consequências em que as drogas acometem aos adolescentes, a saúde pública sofre em ritmo acelerado seu agravamento quando não dispõe de leitos suficientes para internações para esse público ou suas vítimas, sendo necessário em algumas situações, os adolescentes serem encaminhados para instituições de rede privada para a desintoxicação por drogas.

A utilização das drogas pelo público jovem e adolescente, tem acarretado outras vertentes a partir de seu uso, tais como: o aumento da violência extrema pela disputa de espaços para o tráfico e rivalidade de facções criminosas. Nesse sentido, o recrutamento dos mais jovens tem aumentado em vista da proteção e amparo do Estatuto da Criança e do Adolescente em não punir o adolescente em conflito com a lei nos "Art. 103 considera-se ato infracional a conduta descrita como crime ou contravenção penal e Art. 104 são penalmente inimputáveis os menores de dezoito anos, sujeitos às medidas previstas nesta Lei" (BRASIL, 2018, Art. 103/104, 2018, s/p). Conforme Minayo, conceitua violência como: 
[...] violência vem do fato de ela ser um fenômeno da ordem do vivido, cujas manifestações provocam ou são provocadas por uma forte carga emocional de quem a comete, de quem a sofre e de quem a presencia. Por isso, para entender sua dinâmica na realidade brasileira vale a pena fazer uma pausa para compreender a visão que a sociedade projeta sobre o tema, seja por meio da filosofia popular, seja ponto de vista erudito. Os eventos violentos sempre passaram e passam pelo julgamento moral da sociedade (MINAYO, 2010, p.14).

Desse modo, a compreensão da violência acarretada pelos adolescentes em função do uso ou comercialização de drogas e isso passe a refletir com o aumento da criminalidade na sociedade, com inúmeros assaltos onde pessoas comuns são atingidas por armas de fogo, armas brancas ou são brutamente violentadas fisicamente, e ainda, quando sobrevivem os traumas sofridos irão refletir de forma abrupta em suas vidas causando síndromes do pânico e de perseguição.

De acordo com o levantamento de Pesquisas sobre o Consumo de Drogas no Brasil realizado no ano de 2017, por meio de dados epidemiológicos inerentes ao uso e abuso de drogas psicoativas consumidas por adolescentes foi possível analisar a realidade vivenciada no país. Com isso, percebe-se que desde a década de 1980 se tem conhecimento do combate as drogas por meio de pesquisas realizadas nas escolas, grupos populacionais e pessoas em situação de rua, mas, somente em 2001 a nível populacional do país por meio do CEBRID, ou seja, de forma mais subjetiva (SENAD, 2018).

Nesse sentido, o UNODC nos aspectos dos grupos etários concluiu por meio do Relatório o consumo entre os mais jovens comparando aos mais velhos para $\mathrm{O}$ uso das drogas. "A maioria das pesquisas sugere que a adolescência precoce (12-14 anos), a tardia (15-17 anos) é um período de risco crítico para o início do uso de substâncias e pode atingir o pico entre os jovens (com idade entre 18 e 25 anos) " (UNODC, 2018, s/p). Conforme, Castro \& Rosa,

Reconhece a dependência química como doença, porque há alteração da estrutura e no funcionamento normal da pessoa, sendo-lhe prejudicial. Não tem causa única, mas é produto de uma série de fatores (físicos, emocionais, psíquicos e sociais) que atuam ao mesmo tempo, sendo que às vezes, uns são mais predominantes em uma pessoa específica, do que em outras. Atinge o ser humano nas suas três dimensões básicas (biológica, psíquica e social), e atualmente, é reconhecida como uma séria questão social, à medida que atinge 0 mundo inteiro, e todas as classes sociais (CASTRO \& ROSA, 2010, p.10). 
Nesse sentido, identificar as fragilidades das políticas de enfrentamento e combate que impeçam o uso de drogas por adolescentes e seus respectivos acessos seria a melhor estratégia para avançar por um caminho com resultados viáveis para a sociedade. Esse caminho é a informação direta aos adolescentes dos efeitos e consequências dos quais as drogas fazem em seu físico, emoção, comportamento e intelecto.

\section{4 - CONSIDERAÇÕES FINAIS}

Diante do exposto, conclui-se que esta é uma demanda emergente na sociedade, sendo importante e necessário o mapeamento por meio de pesquisas entre indivíduos para o diagnóstico da sua realidade em contato com o mundo das drogas em sua fase inicial para que sejam identificadas as reais necessidades de uma intervenção maior nesses sujeitos, tal como vivem, com quem vivem e do que vivem.

Dessa forma, discutir de forma preventiva com a família, escola e sociedade, sobre as consequências da permanência da utilização das drogas em contextos familiares e educacionais ou na coletividade, sem criar rótulos e estereotipar ao adolescente que se utiliza de drogas para se sentir bem ou fugir da sua realidade existencial, sem criar estereótipos como maconheiro, usuário de droga, viciado, dentre outros.

Sendo assim, é necessário que vários profissionais estejam engajados nesses diversos contextos no intuito de informar e fortalecer a todos os sujeitos como autores de sua própria história e contribuir para o enfrentamento na sociedade para a diminuição das desigualdades sociais no âmbito da questão social na saúde pública e assim, obter de forma positiva os resultados de uma redução de adolescentes envolvidos com drogas no país e reduzir os impactos à saúde pública.

\section{5 - REFERÊNCIAS}

BRASIL. Estatuto da Criança e do Adolescente. Artigos $2^{\circ}, 3^{\circ}, 102^{\circ}, 103^{\circ}$. Disponível em: http://www.planalto.gov.br/CCivil_03/Leis/L8069.htm. Acesso: 22 de novembro de 2018.

CASTRO, Magali Sampaio; ROSA, Lúcia Cristina dos Santos. Prevenção do Uso de Drogas: Adolescência, Família e Escola. Disponível 
http://leg.ufpi.br/subsiteFiles/ppged/arquivos/files/VI.encontro.2010/GT.7/GT_07 _10_2010.pdf

FRASSON, Mariana Cristina Galhardo. A Criminalidade gerada pelo tráfico de drogas. https://marianafrasson.jusbrasil.com.br/artigos/253046155/acriminalidade-gerada-pelo-trafico-de-drogas. Acesso 21 de novembro de 2018.

MARQUES, Ana Cecília Petta Roselli; CRUZ, Marcelo S. 0 adolescente e o uso de drogas. Revista Brasileira Psiquiátrica. 2000; 22 (Supl II):32-6.

MINAYO, Maria Cecília de Souza. Violência e Saúde. Maria Cecília de Souza. Rio de Janeiro. Editora FIOCRUZ, 2006. 132 p. (Coleção Temas em Saúde). 1aㅗ Reimpressão. 2010.

SANTOS, Manoel Antônio dos; PRATTA, Elisângela Maria Machado. Adolescência e uso de drogas à luz da Psicanálise: Sofrimento e êxtase na passagem. Revista Tempo Psicanalítico, Rio de Janeiro. V.44 I, p.167I 82, 2012.

SENAD. Pesquisas sobre o consumo de Drogas no Brasil. Eixo Políticas e Fundamentos. Portal de formação a distância sujeitos; contextos e drogas. Disponível http://www.aberta.senad.gov.br/2018

UNODC. United Nations Office Drugs and Crime. Escritório de Ligação e Parceria no Brasil. Relatório Mundial sobre Drogas 2018: crise de opióides, abuso de medicamentos sob prescrição; cocaína e ópio atingem níveis recordes. Acesso: 21.11.2018. http://www.unodc.org//pobrazil/pt/frontpage/2018/06/relatorio-mundial-drogas-2018.html

VELOSO, Laís Helena Pinto; ABREU, Renata Pacheco. A Questão Social das Drogas e a Prática do Serviço Social (uma proposta de afirmação de direitos e de cidadania). Interagir: pensando a extensão. Rio de Janeiro.n.8.p.11-18.ago/dez 2005.

ZALUAR, Alba. Democratização Inacabada: fracasso da segurança pública. Estudos Avançados 21 (61), 2007. 